\title{
Altered Gut Microbial Fermentation and Colonization with Methanobrevibacter smithii in Renal Transplant Recipients
}

\author{
Tim J. Knobbe ${ }^{1, *}$, Rianne M. Douwes ${ }^{1}\left(\mathbb{D}\right.$, Daan Kremer ${ }^{1}$, J. Casper Swarte ${ }^{1,2} \mathbb{D}$, \\ Michele F. Eisenga ${ }^{1}$, António W. Gomes-Neto ${ }^{1} \mathbb{D}$, Marco van Londen ${ }^{1}{ }^{\mathbb{D}}$, Frans T. M. Peters ${ }^{2}$, \\ Hans Blokzij1 ${ }^{2}$, Ilja M. Nolte ${ }^{3}$, Wouter H. Hendriks ${ }^{4}{ }^{\mathbb{D}}$, Hermie J. M. Harmsen ${ }^{5}$ and \\ Stephan J. L. Bakker ${ }^{1}$ (D) \\ 1 Department of Internal Medicine, Division of Nephrology, University Medical Center Groningen, University \\ of Groningen, 9700 RB Groningen, The Netherlands; r.m.douwes@umcg.nl (R.M.D.); \\ d.kremer@umcg.nl (D.K.); j.c.swarte@umcg.nl (J.C.S.); m.f.eisenga@umcg.nl (M.F.E.); \\ a.w.gomes.neto@umcg.nl (A.W.G.-N.); m.van.londen@umcg.nl (M.v.L.); s.j.l.bakker@umcg.nl (S.J.L.B.) \\ 2 Department of Gastroenterology and Hepatology, University Medical Center Groningen, University of \\ Groningen, 9700 RB Groningen, The Netherlands; f.t.m.peters@umcg.nl (F.T.M.P.); h.blokzijl@umcg.nl (H.B.) \\ 3 Department of Epidemiology, University Medical Center Groningen, University of Groningen, \\ 9700 RB Groningen, The Netherlands; i.m.nolte@umcg.nl \\ 4 Department of Animal Sciences, Wageningen University \& Research centre, 6708 PB Wageningen, \\ The Netherlands; wouter.hendriks@wur.nl \\ 5 Department of Medical Microbiology, University Medical Center Groningen, University of Groningen, \\ 9700RB Groningen, The Netherlands; h.j.m.harmsen@umcg.nl \\ * Correspondence: t.j.knobbe@umcg.nl
}

Received: 23 December 2019; Accepted: 10 February 2020; Published: 14 February 2020

\begin{abstract}
Renal transplant recipients (RTRs) often suffer from posttransplant diarrhea. The observed dysbiosis in RTR may influence the fermentation processes in the gut. In this study, we aimed to investigate whether fermentation differs between RTRs and healthy controls (HCs), by measuring breath $\mathrm{H}_{2}$ and $\mathrm{CH}_{4}$ concentrations. Additionally, we determined the fecal presence of the methanogen Methanobrevibacter smithii (M. smithii), which plays a main role in the process of methanogenesis. Data from the TransplantLines Biobank and Cohort Study (NCT03272841) was used. A total of 142 RTRs and $77 \mathrm{HCs}$ were included. Breath $\mathrm{H}_{2}$ concentrations in RTRs were not significantly different from HCs. Breath $\mathrm{CH}_{4}$ concentrations in RTRs were significantly lower compared with HCs (median [interquartile range (IQR)] 7.5 [3.9-10.6] ppm vs. 16.0 [8.0-45.5] ppm, $p<0.001)$. M. smithii was less frequently present in the feces of RTRs compared to HCs $(28.6 \%$ vs. $86.4 \%$ resp., $p<0.001)$. Our findings regarding the altered methanogenesis in the gut of RTRs show similarities with previous results in inflammatory bowel disease patients. These findings provide novel insight into the alterations of fermentation after renal transplantation, which may contribute to understanding the occurrence of posttransplant diarrhea.
\end{abstract}

Keywords: posttransplant diarrhea; methanogenesis; Methanosphaera stadtmanae; mucins; sulfatereducing bacteria

\section{Introduction}

Renal transplantation is the preferred treatment for patients with end-stage renal disease [1-3]. Part of its success has been made possible by improved therapeutic options, such as ameliorations in surgical techniques and perioperative care [4]. Despite the success of transplantation, the burden of morbidity in renal transplant recipients (RTRs) remains high [5]. 
Patients often experience gastrointestinal complaints such as diarrhea, which is associated with premature kidney allograft failure and mortality, and which affects quality of life $[5,6]$. This posttransplant diarrhea is believed to be non-infectious and induced by the use of medication $[5,7]$. Recently, a study in RTRs showed that dysbiosis in the gut might cause or contribute to this posttransplant diarrhea [7]. Lee et al. demonstrated in this study that the gut microbiota diversity of RTRs with diarrhea was significantly lower than in RTRs without diarrhea. In addition, RTRs with diarrhea had a lower diversity of commensal bacterial taxa in the gut, creating a dysfunctional metabolic state. These commensal bacterial taxa are important for the degradation of complex molecules such as complex carbohydrates. During this degradation, among many other molecules, short-chain fatty acids are produced, which contributes to overall gut health $[8,9]$. It has been proposed that posttransplant diarrhea might be the consequence of a diminished ability to digest complex sugars [7]. A proportion of complex polymers such as fibers escape digestion and absorption in the small bowel. These complex polymers are then fermented to short-chain fatty acids (acetate, butyrate and propionate) and gases (hydrogen $\left(\mathrm{H}_{2}\right)$ and carbon dioxide $\left(\mathrm{CO}_{2}\right)$ ) [10].

In order to maintain fermentation, it is essential that $\mathrm{H}_{2}$ concentration is reduced by $\mathrm{H}_{2}$-consuming microorganisms [11]. $\mathrm{H}_{2}$ can be used as an electron donor in sulfate respiration, methanogenesis or acetogenesis to produce hydrogen sulfide $\left(\mathrm{H}_{2} \mathrm{~S}\right)$, methane $\left(\mathrm{CH}_{4}\right)$ and acetate, respectively [12]. Production of $\mathrm{H}_{2} \mathrm{~S}$ is most favorable, followed by the production of $\mathrm{CH}_{4}$ and acetate, respectively. However, for the production of $\mathrm{H}_{2} \mathrm{~S}$, the presence of sulfate is necessary [13]. The production of $\mathrm{CH}_{4}$ is performed by archaea. Methanobrevibacter smithii (M. smithii) and Methanosphaera stadtmanae (M. stadtmanae) are the two methanogens usually detected in the human gut. M. smithii is the predominant methanogen in the human colon [14]. Next to $\mathrm{H}_{2,}$, formate can be used for the methanogenesis as well [15]. The produced $\mathrm{CH}_{4}$ and the remaining $\mathrm{H}_{2}$ are excreted in breath and flatus. Therefore, both gases can be measured in exhaled breath [13]. Measuring breath $\mathrm{CH}_{4}$ concentrations is a simple way to investigate the metabolism of intestinal methanogens, since no significant catabolism elsewhere in the human body has been observed [12]. The presence of $M$. smithii can be measured in the feces, as has previously been performed in studies investigating patients suffering from inflammatory bowel disease (IBD) [12,16].

The dysbiosis in RTRs may influence the fermentation in the gut and the processes following fermentation, possibly leading to or contributing to posttransplant diarrhea. To gain more insight into pathogenesis of this diarrhea, we aimed to investigate the fermentation and methanogenesis in the gut in RTRs. Firstly, we aimed to investigate whether breath $\mathrm{H}_{2}$ and $\mathrm{CH}_{4}$ concentrations differ between RTRs and HCs. Secondly, we aimed to investigate whether the presence of M. smithii in feces differs between RTRs and HCs, and finally we aimed to identify the determinants of $\mathrm{CH}_{4}$ production.

\section{Methods}

\subsection{Study Population}

For this study we used data from the TransplantLines Biobank and Cohort Study (ClinicalTrials.gov identifier: NCT03272841). A detailed description of the study design, inclusion and exclusion criteria has been described previously [17]. In addition to the standard protocol, we measured breath $\mathrm{H}_{2}$ and $\mathrm{CH}_{4}$ concentrations and analyzed the presence of $M$. smithii in feces for the current study. (Potential) living organ donors were used as a healthy control group for comparison. Our inclusion period was between February and December 2017. The study protocol has been approved by the Institutional Review Board (METc 2014/077) (METc UMCG), adheres to the UMCG Biobank Regulation, and is in accordance with the WMA Declaration of Helsinki and the Declaration of Istanbul [17].

\subsection{Patient Comorbidities}

Diabetes mellitus was defined according to the guidelines of the American Diabetes Association [18]. The estimated glomerular filtration rate (eGFR) was calculated using the serum creatinine-based chronic 
kidney disease epidemiology collaboration (CKD-EPI) formula. Data regarding the history of allograft rejection and primary renal disease before transplantation were retrieved from patients' medical files.

\subsection{Breath $\mathrm{H}_{2}$ and $\mathrm{CH}_{4}$ Concentration Measurement}

For $\mathrm{H}_{2}$ and $\mathrm{CH}_{4}$ measurements, breath samples were collected using a $50 \mathrm{cc}$ syringe with an opening of $6 \mathrm{~mm}$ in diameter at approximately $40 \mathrm{cc}$ with a 3-way-stopcock. Subjects were instructed to inhale normally and exhale fully in the syringe, with the plunger set at $50 \mathrm{cc}$ and the 3-way stopcock open. After full expiration, the opening was immediately closed by the subject's finger, the plunger was set to $30 \mathrm{cc}$ and the 3-way stopcock was closed. This resulted in breath samples that were not diluted by environmental air. Two breath samples were taken subsequently per study subject. Breath samples were analyzed within $12 \mathrm{~h}$ after sample collection. $\mathrm{H}_{2}, \mathrm{CH}_{4}$ and $\mathrm{CO}_{2}$ measurements were performed using a solid-state gas-chromatography device (Breathtracker SC, QuinTron Instrument Company, Inc., Milwaukee, WI, USA). The device separates the components by the basic principle of gas chromatography, using room air as the carrier gas, which is pumped through the system by an internal circulating pump. $\mathrm{H}_{2}$ and $\mathrm{CH}_{4}$ are separated from all other reducing gases and from each other, and are carried past a solid-state sensor [19]. The sensors are reported to be affected only by reducing gases, so it is unaffected by other gases in the sample; it can also employ a $\mathrm{CO}_{2}$ correction factor [19]. The analytical sensitivity is $1 \mathrm{ppm}$ for $\mathrm{H}_{2}$ and $\mathrm{CH}_{4}$ and $0.1 \%$ for $\mathrm{CO}_{2}$. The Breathtracker has a linear analytical range of 2-150 ppm for $\mathrm{H}_{2}, 2-75 \mathrm{ppm}$ for $\mathrm{CH}_{4}$ and $1000-70,000 \mathrm{ppm}$ for $\mathrm{CO}_{2}$. To ensure reliable breath measurements, study subjects were not allowed to smoke for at least one hour before the sample collection [20].

\subsection{Smithii Measurement in Feces}

Fecal samples were collected the day prior to the TransplantLines visit, using a FecesCatcher (TAG Hemi VOF, Zeijen, The Netherlands) and were immediately frozen after collection. The feces samples were transported in cold storage to the TransplantLines visit, and immediately stored at $-80^{\circ} \mathrm{C}$ $\left(-112^{\circ} \mathrm{F}\right)$ [17]. After thawing, DNA was extracted with the RBB and Qiagen method, as performed by Yu et al. with modifications described by de Goffau et al. [21,22]. To measure the quantity of M. smithii, real-time quantitative reverse transcription polymerase chain reaction (RT-PCR) (7500 real time PCR system, applied Biosystems, Thermo Fisher Scientific, Waltham, USA) was performed. Primers were taken as described by Johnston et al., and differentiation between M. smithii and other organisms in the sample was assessed using nifH genes [23]. The number of nifH genes are equal to the number of M. smithii, since only one gene of nifH is present in each M. smithii [24]. Analyses were performed using the Taqman machine and processed using SDSShell (Applied Biosystems, Thermo Fisher Scientific, Waltham, USA). The quantifiable presence of $M$. smithii was determined using a cycle threshold value. Values $<40$ cycles were regarded as positive, and values $\geq 40$ were regarded as negative. For analyses, CT-values $\geq 40$ were regarded as negative and concentrations of $M$. smithii in these patients were regarded as 0 M. smithii/gram feces. A detailed method description is attached in Supplementary File 1.

\subsection{Statistical Analyses}

Statistical analyses were performed using the Statistical Package for the Social Sciences (SPSS) version 23.0 (IBM corp.; Armonk, NY, USA). In all analyses, $p<0.05$ was regarded as statistically significant. Categorical variables are presented as $n(\%)$, normally distributed variables as mean \pm standard deviation (SD) and non-normally distributed variables as median [interquartile range]. Normality was assessed using Q-Q plots. Differences between groups with normally distributed variables were assessed using independent T-tests. Non-normally distributed data were compared using the Mann-Whitney $U$ test. Comparison of categorical variables was performed using a chi-square test for groups with $n \geq 5$ and a Fisher's exact test for groups with $n<5$. For all other tests and visualizations, the mean of the duplicate measurements of the breath $\mathrm{H}_{2}$ and $\mathrm{CH}_{4}$ concentration in breath was used. To correct for environmental $\mathrm{CH}_{4}, 2 \mathrm{ppm}$ was subtracted from each breath 
$\mathrm{CH}_{4}$-measurement [25,26]. Possible determinants of breath $\mathrm{CH}_{4}$ were identified using univariable linear regression. All variables with a $p$-value $<0.2$ were included in a multivariable linear regression model run backward to identify the determinants of breath $\mathrm{CH}_{4}$ production. Because $\mathrm{H}_{2}$ is used by M. smithii for the conversion to $\mathrm{CH}_{4}$, an interaction term of $\mathrm{H}_{2}$ and M. smithii was added in the analysis. $\log _{10}$ transformations were performed if necessary to reach conditions in all performed analyses.

\section{Results}

We included 219 study subjects, of whom 142 (64.8\%) were RTRs and 77 (35.2\%) were HCs. Among RTRs, 91 (64.1\%) were male, and the mean age was $56.3 \pm 13.7$ years. Among HCs, 39 (50.6\%) were male, and the mean age was $56.4 \pm 10.6$ years. Baseline characteristics are shown in Table 1. A Consort Flow diagram is presented to provide an overview of subgroups that were used in different analyses (Figure 1). Breath $\mathrm{H}_{2}$ concentrations of the RTRs were not significantly different compared with HCs (Table 1). The RTRs had, however, lower breath $\mathrm{CH}_{4}$ concentrations compared to the HCs (7.5 [3.9-10.6] ppm vs. 16.0 [8.0-45.5] ppm, $p<0.001$ ). Data distributions of breath $\mathrm{H}_{2}$ and $\mathrm{CH}_{4}$ concentrations are shown in Supplementary File 2. Raw data are shown in the Supplementary data.

Table 1. Baseline characteristics.

\begin{tabular}{|c|c|c|c|}
\hline Characteristics & $\begin{array}{l}\text { Renal Transplant } \\
\text { Recipients }\end{array}$ & Healthy Controls & $p$-Value \\
\hline Number of subjects, $n(\%)$ & $142(64.8)$ & $77(35.2)$ & $n / a$ \\
\hline \multicolumn{4}{|l|}{ Fermentation parameters } \\
\hline Breath $\mathrm{H}_{2}$ concentration, ppm & $11.3[4.0-30.0]$ & $10.5[4.5-28.3]$ & 0.9 \\
\hline Breath $\mathrm{CH}_{4}$ concentration, ppm & $7.5[3.9-10.6]$ & $16.0[8.0-45.5]$ & $<0.001$ \\
\hline $\begin{array}{l}\text { Quantifiable abundance of M. smithii in feces, } n \\
\text { (valid \%) }\end{array}$ & $22(28.6)$ & $38(86.4)$ & $<0.001$ \\
\hline $\begin{array}{c}\text { Abundance of } M \text {. smithii in feces samples, } M \text {. } \\
\text { smithii/gram }\end{array}$ & $\begin{array}{c}0.0 \\
{\left[0.0-4.0 \times 10^{5}\right]}\end{array}$ & $\begin{array}{c}5.9 \times 10^{7} \\
{\left[1.2 \times 10^{6}-8.9 \times 10^{8}\right]}\end{array}$ & $<0.001$ \\
\hline \multicolumn{4}{|l|}{ Demographics } \\
\hline Age, $y$ & $56.3 \pm 13.7$ & $56.4 \pm 10.6$ & 0.6 \\
\hline Number of males, $n(\%)$ & $91(64.1)$ & $39(50.6)$ & 0.05 \\
\hline BMI, $\mathrm{kg} / \mathrm{m}^{2}$ & $28.0 \pm 5.2$ & $26.4 \pm 3.8$ & 0.01 \\
\hline \multicolumn{4}{|l|}{ Lifestyle parameters } \\
\hline Current smokers, $n$ (valid \%) & $23(16.7)$ & $14(18.9)$ & 0.4 \\
\hline Alcohol intake per day, units & $0.0[0.0-0.2]$ & $0.25[0.0-0.5]$ & 0.003 \\
\hline \multicolumn{4}{|l|}{ Laboratory parameters } \\
\hline Hemoglobin, g/dL & $13.8 \pm 1.9$ & $14.4 \pm 1.3$ & 0.008 \\
\hline Hematocrit, L/L & $0.42 \pm 0.06$ & $0.43 \pm 0.04$ & 0.2 \\
\hline Leukocytes, $10^{9} / \mathrm{L}$ & $7.4 \pm 2.5$ & $6.5 \pm 1.9$ & $<0.003$ \\
\hline Platelets, $10^{9} / \mathrm{L}$ & $250.6 \pm 78.4$ & $261.2 \pm 56.6$ & 0.3 \\
\hline C-reactive protein, $\mathrm{mg} / \mathrm{L}$ & $2.3[1.1-5.0]$ & $1.2[0.8-4.0]$ & 0.035 \\
\hline Albumin, $\mathrm{g} / \mathrm{L}$ & $44.2 \pm 3.1$ & $45.4 \pm 2.5$ & 0.003 \\
\hline Glucose, mmol/L & $6.0 \pm 1.7$ & $5.5 \pm 0.7$ & 0.005 \\
\hline $\mathrm{HbA} 1 \mathrm{c}, \mathrm{mmol} / \mathrm{mol}$ & $42.3 \pm 7.8$ & $36.9 \pm 3.5$ & $<0.001$ \\
\hline $\mathrm{eGFR}, \mathrm{ml} / \mathrm{min} / 1.73 \mathrm{~m}^{2}$ & $49.8 \pm 16.5$ & $69.3 \pm 18.7$ & $<0.001$ \\
\hline Creatinine, $\mu \mathrm{mol} / \mathrm{L}$ & 130 [103.0-156.8] & $92.0[81.0-106.0]$ & $<0.001$ \\
\hline Urea, mmol/L & $9.4 \pm 4.4$ & $5.8 \pm 1.6$ & $<0.001$ \\
\hline \multicolumn{4}{|l|}{ Medication use } \\
\hline Antibiotics, $n(\%)$ & $37(16.9)$ & $0(0.0)$ & $<0.001$ \\
\hline \multicolumn{4}{|l|}{ Immunosuppressants, $n(\%)$} \\
\hline Prednisolone, $n(\%)$ & $140(98.6)$ & - & $n / \mathrm{a}$ \\
\hline Mycophenolate mofetil, $n(\%)$ & $112(78.9)$ & - & $n / \mathrm{a}$ \\
\hline Tacrolimus, $n(\%)$ & $102(71.8)$ & - & $n / \mathrm{a}$ \\
\hline
\end{tabular}


Table 1. Cont.

\begin{tabular}{cccc}
\hline Characteristics & $\begin{array}{c}\text { Renal Transplant } \\
\text { Recipients }\end{array}$ & Healthy Controls & $p$-Value \\
\hline Cyclosporine, $n(\%)$ & $14(9.9)$ & - & $n / \mathrm{a}$ \\
Everolimus, $n(\%)$ & $7(4.9)$ & - & $n / \mathrm{a}$ \\
Azathioprine, $n(\%)$ & $10(7.0)$ & - & $n / \mathrm{a}$ \\
Statins, $n(\%)$ & $70(49.3)$ & $8(10.4)$ & $<0.001$ \\
Proton pump inhibitors, $n(\%)$ & $108(76.1)$ & $0(0.0)$ & $<0.001$ \\
Insulin, $n(\%)$ & $11(7.8)$ & $0(0.0)$ & 0.009 \\
Biguanides, $n(\%)$ & $7(4.9)$ & $0(0.0)$ & 0.09 \\
Macrogol, $n(\%)$ & $8(5.6)$ & $1(1.3)$ & 0.200 \\
Lactulose, $n(\%)$ & $2(1.4)$ & $0.0 .0)$ & 1.000 \\
Loperamide, $n(\%)$ & $1(0.7)$ & $4(5.2)$ & 0.4 \\
Antidepressants, $n(\%)$ & $16(7.3)$ & - & $n / \mathrm{a}$ \\
Unknown, $n(\%)$ & $23(16.2)$ & & $n / \mathrm{a}$ \\
Inflammatory disease & $55(38.7)$ & - & $n / \mathrm{a}$ \\
Primary renal disease before transplantation & $41(28.9)$ & - & $n / \mathrm{a}$ \\
Renal vascular disease, excluding vasculitis, $n(\%)$ & $13(9.2)$ & - & $<0.001$ \\
Diabetic nephropathy, $n(\%)$ & $10(7.0)$ & & $n / \mathrm{a}$ \\
Diabetes mellitus, $n(\%)$ & $27(19.0)$ & $1(1.3)$ & - \\
History of allograft rejection, $n(\%)$ & $14(9.9)$ & & \\
\hline
\end{tabular}

Data are presented as mean \pm standard deviation (SD), median with interquartile ranges (IQRs) or number with percentages (\%). Abbreviations: BMI, body mass index; eGFR, estimated glomerular filtration rate; $\mathrm{CH}_{4}$, methane; $\mathrm{H}_{2}$, hydrogen; HbA1c, hemoglobin A1c; M. smithii, Methanobrevibacter smithii.

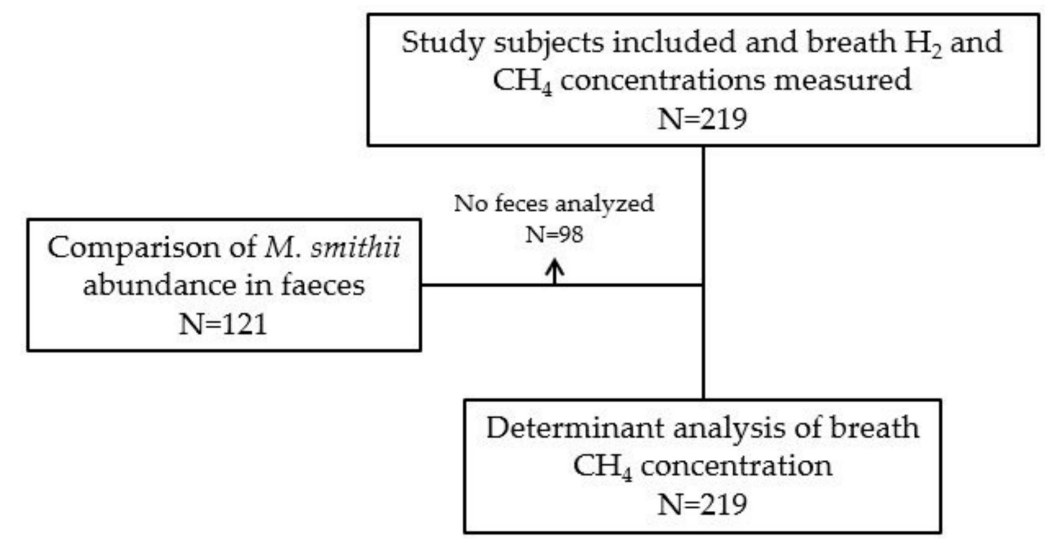

Figure 1. Consort flow diagram. Abbreviations: $\mathrm{CH}_{4}$, methane; $\mathrm{H}_{2}$, hydrogen; M. smithii, Methanobrevibacter smithii.

\subsection{Smithii in Feces}

The feces of 98 study subjects was not available for analysis. M. smithii abundance was analyzed in the feces samples of 77 RTRs and 44 HCs (i.e., 121 of 219 study subjects, see Figure 1). Among the RTRs, $22(28.6 \%)$ had quantifiable concentrations of M. smithii in their stool samples. Among HCs, $38(86.4 \%)$ had quantifiable concentrations of $M$. smithii in their feces samples. The median abundance of M. smithii in the feces of those study subjects was $5.9 \times 10^{7}\left[1.2 \times 10^{6}-8.9 \times 10^{8}\right]$ per gram feces. A quantifiable concentration of $M$. smithii was significantly less frequently observed in RTRs compared to HCs $((22(28.6 \%)$ vs. $38(86.4 \%)$ resp.; $p<0.001)$ (Table 1$)$. In addition, the abundance of $M$. smithii was positively correlated with breath $\mathrm{CH}_{4}$ concentrations $(r=0.69, p<0.001)$. 


\subsection{Determinants of Breath $\mathrm{CH}_{4}$}

Determinants of breath $\mathrm{CH}_{4}$ were analyzed using linear regression analysis in all 219 study subjects, and these results are presented in Table 2. Breath $\mathrm{H}_{2}$ and the presence of a quantifiable abundance of $M$. smithii in feces were associated with higher breath $\mathrm{CH}_{4}$ concentrations (standardized beta (st. $\beta$ ) $0.57, p<0.001$ and st. $\beta 0.94, p<0.001$ resp.). A negative interaction was found between both determinants on breath $\mathrm{CH}_{4}$ (st. $\beta-0.51, p=0.001$ ), indicating that in the presence of M. smithii the magnitude of the correlation between $\mathrm{H}_{2}$ and $\mathrm{CH}_{4}$ in breath decreases from overt to virtually absent $(r=0.88, p<0.001$ vs. $r=0.09, p=0.5$ resp., Figure 2$)$. In addition, the use of mycophenolate mofetil was associated with a lower breath $\mathrm{CH}_{4}$ concentration (st. $\beta-0.18, p=0.014$ ). The described determinants explained $55.0 \%$ of the total variation in breath $\mathrm{CH}_{4}$ concentrations.

Table 2. Linear regression analysis of $\log _{10}$ breath $\mathrm{CH}_{4}$ concentration.

\begin{tabular}{|c|c|c|c|c|}
\hline & \multicolumn{2}{|c|}{$\begin{array}{l}\text { Univariable Linear } \\
\text { Regression Analysis }\end{array}$} & \multicolumn{2}{|c|}{$\begin{array}{l}\text { Multivariable Linear } \\
\text { Regression Analysis* }\end{array}$} \\
\hline & St. $\beta$ & $p$-Value & St. $\beta$ & $p$-Value \\
\hline A medical history of renal transplantation (yes vs. no) & -0.42 & $<0.001$ & & \\
\hline \multicolumn{5}{|l|}{ Fermentation parameters } \\
\hline $\log _{10}$ Breath $\mathrm{H}_{2}, \mathrm{ppm}$ & 0.32 & $<0.001$ & 0.54 & $<0.001$ \\
\hline Quantifiable abundance of $M$. smithii in feces (yes vs. no) & 0.55 & $<0.001$ & 0.95 & $<0.001$ \\
\hline $\begin{array}{c}\text { Interaction between } \log _{10} \text { breath } \mathrm{H}_{2} \text { and M. smithii in feces } \\
\text { Demographics }\end{array}$ & 0.48 & $<0.001$ & -0.51 & 0.001 \\
\hline Age, y & 0.07 & 0.3 & & \\
\hline Gender (yes vs. no) & -0.02 & 0.7 & & \\
\hline BMI, $\mathrm{kg} / \mathrm{m}^{2}$ & -0.18 & 0.012 & & \\
\hline $\mathrm{eGFR}, \mathrm{mL} / \mathrm{min} / 1.73 \mathrm{~m}^{2}$ & 0.25 & $<0.001$ & & \\
\hline \multicolumn{5}{|l|}{ Intoxications } \\
\hline Smoking (yes vs. no) & -0.10 & 0.1 & & \\
\hline Alcohol (units per day) & -0.01 & 0.9 & & \\
\hline \multicolumn{5}{|l|}{ Medication use (yes vs. no) } \\
\hline Antibiotics & -0.12 & 0.1 & & \\
\hline \multicolumn{5}{|l|}{ Immunosuppressive medication (yes vs. no) } \\
\hline Prednisolone & -0.40 & $<0.001$ & & \\
\hline Mycophenolate mofetil & -0.36 & $<0.001$ & -0.18 & 0.014 \\
\hline Tacrolimus & -0.27 & $<0.001$ & & \\
\hline Cyclosporine & -0.06 & 0.4 & & \\
\hline Azathioprine & 0.00 & 1.0 & -0.10 & 0.1 \\
\hline Everolimus & 0.04 & 0.5 & & \\
\hline Statins & -0.15 & 0.024 & & \\
\hline Proton pump inhibitors & -0.26 & $<0.001$ & & \\
\hline Macrogol & 0.06 & 0.4 & & \\
\hline Lactulose & 0.10 & 0.1 & & \\
\hline Loperamide & 0.02 & 0.8 & & \\
\hline Biguanide drugs & -0.04 & 0.6 & & \\
\hline Insulin & -0.05 & 0.5 & & \\
\hline Antidepressants & -0.14 & 0.044 & & \\
\hline \multicolumn{5}{|l|}{ Primary renal disease of RTR (yes vs. no) } \\
\hline Unknown & -0.04 & 0.6 & & \\
\hline Inflammatory disease & 0.02 & 0.8 & & \\
\hline Congenital and hereditary kidney disease & 0.00 & 1.0 & & \\
\hline Renal vascular disease, excluding vasculitis & 0.09 & 0.3 & & \\
\hline Diabetes Mellitus & -0.08 & 0.3 & & \\
\hline \multicolumn{5}{|l|}{ Others (yes vs. no) } \\
\hline Suffering from Diabetes Mellitus & -0.06 & 0.4 & & \\
\hline History of allograft rejection & -0.02 & 0.8 & & \\
\hline
\end{tabular}

Abbreviations: BMI, body mass index; eGFR, estimated glomerular filtration rate; $\mathrm{CH}_{4}$, methane; $\mathrm{H}_{2}$, hydrogen; M. smithii, Methanobrevibacter smithii; St. $\beta$, standardized beta. $R^{2}=0.550 .{ }^{*}$ Run backwards. 


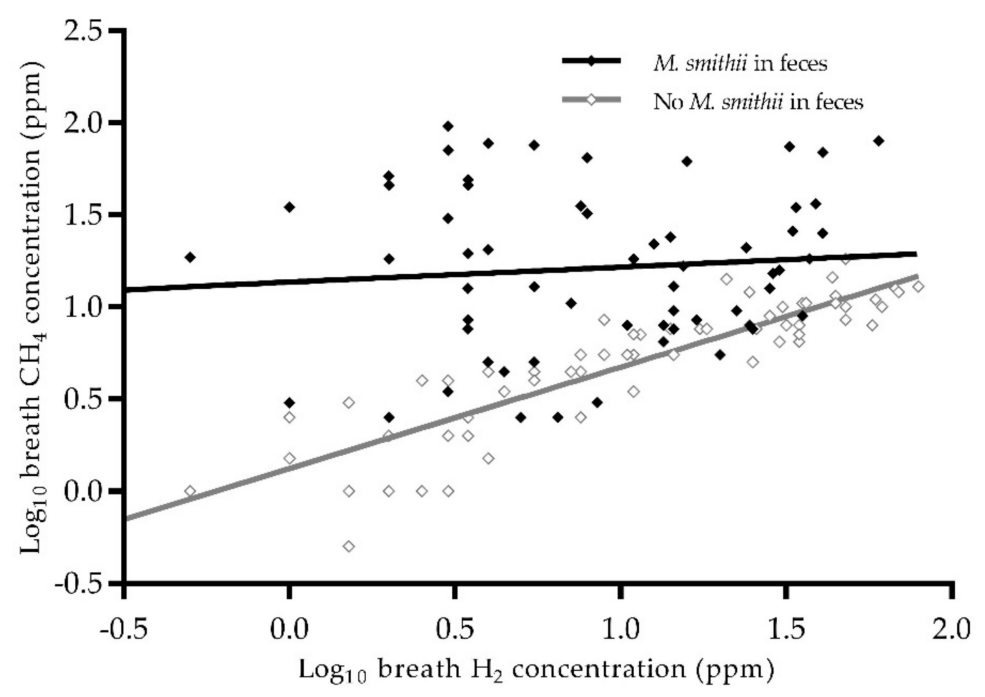

Figure 2. Scatterplot of $\log _{10}$ breath $\mathrm{H}_{2}$ and $\mathrm{CH}_{4}$ concentration by presence of $M$. smithii in feces. There is a difference between the relation between $\mathrm{H}_{2}$ and $\mathrm{CH}_{4}$ in subjects with and without $M$. smithii. Abbreviations: $\mathrm{CH}_{4}$, methane; $\mathrm{H}_{2}$, hydrogen; M. smithii, Methanobrevibacter smithii. $\mathrm{N}=121$. Pearson correlation in the absence of M. smithii, $r=0.88, p<0.001$. Pearson correlation in the presence of M. smithii, $r=0.09, p=0.5$.

\section{Discussion}

We have shown that although no significant difference in breath $\mathrm{H}_{2}$ concentration was found between RTRs and HCs, breath $\mathrm{CH}_{4}$ concentrations were significantly lower in the RTRs compared with the HCs. In addition, we found a significantly lower presence of M. smithii in the feces of RTRs compared with HCs. Breath $\mathrm{H}_{2}$ and the presence of $M$. smithii in feces were associated with higher breath $\mathrm{CH}_{4}$ concentrations. Moreover, the association between breath $\mathrm{H}_{2}$ and $\mathrm{CH}_{4}$ concentrations disappeared in presence of $M$. smithii in feces. Finally, mycophenolate mofetil was associated with a lower breath $\mathrm{CH}_{4}$ concentration.

The reduced breath $\mathrm{CH}_{4}$ concentration in RTRs compared to HCs which we observed might be explained by the reduced presence of $M$. smithii in the feces of RTRs, since M. smithii is the most abundant methanogen in the human gut [12]. One reason for the lower prevalence of M. smithii in the feces of RTRs may be the result of an increased presence or activity of sulfate-reducing bacteria (SRB). It has been described that a high concentration of either methanogens or sulfate-reducing bacteria is present in the feces of healthy individuals. These two groups of microorganisms appear to be competing for $\mathrm{H}_{2}$, with the prevailing group becoming the predominant organism $[27,28]$. However, since no mechanism of direct competition between SRB, methanogens and acetogens has been observed, at this point it is impossible to predict any dominance of one of these hydrogenotrophs [29]. If the gut in RTRs is more colonized with SRB, or if these SRB are more active, more hydrogen sulfide $\left(\mathrm{H}_{2} \mathrm{~S}\right)$ is produced. $\mathrm{H}_{2} \mathrm{~S}$ is highly toxic to the colonocytes and impairs their metabolic function, especially the butyrate oxidation [30]. Butyrate has a known anti-inflammatory effect and several other health-promoting functions [31]. The presence of butyrate in the lumen and the oxidation by colonocytes are both involved in the regulation of water and sodium absorption from the colon [30]. SRB and the consequent disturbance of butyrate oxidation is believed to play a key role in the pathogenesis of IBD [12]. If SRB are indeed more present in RTRs, this might also be an explanatory factor for the occurrence of any of the gastrointestinal complaints of RTRs [16], especially since the butyrate concentration in RTRs seems to be lower due to the reduced prevalence of bacteria taxa that produce butyrate [7].

In addition, more colonization with $\mathrm{SRB}$, and consequently more $\mathrm{H}_{2} \mathrm{~S}$, may diminish the positive effects of the butyrate in the gut of RTRs. However, the presence of SRB was not measured in this study. Although our results regarding the decreased presence of $M$. smithii do support this hypothesis, future studies will have to further test this hypothesis. 
Another reason for the lower prevalence of $M$. smithii in feces might be a lower presence of mucins in the gut of RTRs. We observed no significant correlation between breath $\mathrm{H}_{2}$ and $\mathrm{CH}_{4}$ concentrations in the presence of M. smithii. Therefore, the produced $\mathrm{CH}_{4}$ by M. smithii may be derived from endogenous substrates such as mucins, formate or other unknown substrates [12,32]. Importantly, for mucins it has not yet been settled whether they contribute to methane production or rather inhibit it, or under which circumstances stimulation may shift towards inhibition [32,33]. Mucins cover the epithelium and form a protective layer in the gut, thereby providing a protective layer against pathogenic organisms [34]. Deficiencies of mucin in the intestinal barrier are associated with an abnormal mucosal inflammatory response, which is present in IBD [34]. The role of mucins in the fermentation processes in RTRs has, to our best knowledge, never been investigated.

We also observed a strong correlation between breath $\mathrm{H}_{2}$ and $\mathrm{CH}_{4}$ concentrations in the absence of M. smithii in feces (Figure 2). Possibly, other methanogens that flourish in the absence of M. smithii are more dependent upon $\mathrm{H}_{2}$ concentrations. One of these methanogens might be M. stadtmanae, an archaeon that is the second most common archaeon in the healthy gut after M. smithii [35]. It is known that the $\mathrm{CH}_{4}$ production by $M$. stadtmanae is highly dependent upon the presence of $\mathrm{H}_{2}$ and methanol $[36,37]$. An increased prevalence of $M$. stadtmanae has been observed previously in IBD patients in a study by Lecours et al. [38]. Interestingly, it has been reported that $M$. stadtmanae can induce an inflammatory cytokine response from monocyte-derived dendritic cells, which may contribute to pathological conditions in the gut [39]. In order to gain more insight into gut health in RTRs, the prevalence of $M$. stadtmanae needs to be further investigated [12,39,40].

In addition, our study shows that patients using mycophenolate mofetil exhale lower concentrations of $\mathrm{CH}_{4}$. Previous studies have shown that mycophenolate mofetil is associated with gastrointestinal injury and diarrhea, although any underlying mechanisms are incompletely understood [6]. Lower $\mathrm{CH}_{4}$ levels are also associated with diarrhea [12]. Future studies may investigate whether methanogenesis plays a role in the association between mycophenolate mofetil and diarrhea.

Our observations are in line with previous studies in IBD patients [12,41]. This is interesting, since RTRs and IBD patients have similarities: both groups suffer from intestinal dysbiosis, often have diarrhea and often need to take immunosuppressive medication [38,42-44]. Scanlan et al. observed a significantly lower presence of methanogen-positive feces samples in patients suffering from ulcerative colitis compared to healthy controls ( $24 \%$ versus $48 \%$ ). In addition, a lower presence of methanogens in patients suffering from Crohn's disease was observed (30\% versus $48 \%$ ), although this association was not statistically significant [41]. In another study by Ghavami et al., significantly higher amounts of M. smithii were found in the feces samples of HCs compared to IBD patients [16]. Our results suggest that the reduced colonization with M. smithii, and possibly the methanogenesis of IBD patients, might be comparable to RTRs.

It is known that $\mathrm{CH}_{4}$ reduces inflammation, oxidative stress and apoptosis in the human body [45]. Our findings show significantly lower breath $\mathrm{CH}_{4}$ concentrations in RTRs compared to HCs, while the protective properties of $\mathrm{CH}_{4}$ appear especially important in RTRs in the context of (prevention of) renal rejection, inflammation and high levels of oxidative stress [46]. Future studies may further investigate the associations of (breath) $\mathrm{CH}_{4}$ concentrations with patient outcomes, such as renal rejection. If the hypotheses regarding the protective properties of $\mathrm{CH}_{4}$ are confirmed, the relatively low $\mathrm{CH}_{4}$ levels in RTR may be a therapeutic target, since $\mathrm{CH}_{4}$ concentrations in the body can be increased iatrogenically by inhalation or injection $[47,48]$.

No difference in breath $\mathrm{H}_{2}$ concentration was found in the current study. This is in line with other studies: the matter of hydrogenotrophics in the gut is highly complex, and is dependent upon many variables [49].

It is a limitation of our study that we did not measure mucin concentrations or potential colonization by SRB or M. stadtmanae. In addition, we did not measure $\mathrm{H}_{2}$ and $\mathrm{CH}_{4}$ concentrations in flatus, although it has been found that the concentration of both gases are higher in flatus than in breath when the concentrations are high [50]. No data regarding menopausal status was available in our study, 
although it is known that menopausal status does affect the gut microbiome [51]. Additionally, we did not measure breath $\mathrm{H}_{2}$ and $\mathrm{CH}_{4}$ concentrations and the abundance of $M$. smithii in the feces of RTRs before transplantation. Further limitations of our study are that it was performed in a single center, and that our RTRs were included at different time points after transplantation. Another limitation of this study is that for logistical reasons we were unable to analyze M. smithii in the feces of all our study subjects. In addition, although we measured the breath $\mathrm{H}_{2}$ concentrations in the morning, shortly after breakfast, it was in a non-fasting state. Finally, the current study uses cross-sectional data, and therefore no conclusions regarding causal relationships can be drawn.

\section{Conclusions}

To the best of our knowledge, this is the first study to investigate both breath and feces samples in RTRs. The study shows that breath $\mathrm{CH}_{4}$ concentration and the prevalence of $M$. smithii in feces are significantly lower in RTRs compared to HCs. Our findings regarding the altered methanogenesis in the gut of RTRs show significant similarities with previous results in IBD patients. We observed that in the absence of M. smithii, breath $\mathrm{CH}_{4}$ production is highly dependent on $\mathrm{H}_{2}$ concentration, while this is not the case in the presence of $M$. smithii. Apparently, methanogenesis differs significantly depending on presence of M. smithii. Finally, the use of mycophenolate mofetil was associated with methanogenesis. These findings provide novel insight into the alterations of fermentation after renal transplantation, which may contribute to the occurrence of posttransplant diarrhea. In addition, this study has raised important hypotheses regarding the potential role of SRB and M. stadtmanae in post-transplant diarrhea. Future studies are needed to investigate the role of SRB and M. stadtmanae. Additionally, future research may study whether altered methanogenesis is associated with clinical outcomes, such as posttransplant diarrhea.

Supplementary Materials: The following are available online at http://www.mdpi.com/2077-0383/9/2/518/s1, Supplementary File 1: extended description of the methods used to quantify the number of M. smithii in fecal samples, Supplementary File 2: data distributions of breath $\mathrm{H}_{2}$ and $\mathrm{CH}_{4}$ concentrations, Supplementary data: raw data.

Author Contributions: Data curation, T.J.K., R.M.D., M.F.E., A.W.G.-N., M.v.L., J.C.S. and S.J.L.B.; formal analysis T.J.K., R.M.D., D.K. and S.J.L.B.; methodology T.J.K., R.M.D., M.F.E., A.W.G.-N., M.v.L. and S.J.L.B.; writing - original draft preparation, T.J.K. and D.K.; writing-review and editing, T.J.K., R.M.D., D.K., J.C.S., M.F.E., A.W.G.-N., M.v.L., F.T.M.P., H.B., I.M.N., W.H.H., H.J.M.H. and S.J.L.B.; supervision, S.J.L.B. All authors have read and agreed to the published version of the manuscript.

Funding: R.M. Douwes is supported by NWO/TTW in a partnership program with DSM, Animal Nutrition and Health, The Netherlands; grant number: 14939.

Conflicts of Interest: The authors declare no conflict of interest. The funder had no role in the design of the study; in the collection, analyses, or interpretation of data, in the writing of the manuscript, or in the decision to publish the results.

\section{References}

1. Laupacis, A.; Keown, P.; Pus, N.; Krueger, H.; Ferguson, B.; Wong, C. MN A Study of Quality of Life and Cost Utility Analysis of Tx. Kidney Int. 1996, 50, 235-242. [CrossRef] [PubMed]

2. Jofré, R.; López-Gómez, J.M.; Moreno, F.; Sanz-Guajardo, D.; Valderrábano, F. Changes in quality of life after renal transplantation. Am. J. Kidney Dis. 1998, 32, 93-100. [CrossRef] [PubMed]

3. Wolfe, R.A.; Ashby, V.B.; Milford, E.L.; Ojo, A.O.; Ettenger, R.E.; Agodoa, L.Y.; Held, P.J.; Port, F. Comparison of mortality in all patients on dialysis, patients on dialysis awaiting transplantation, and recipients of a first cadaveric transplant. N. Engl. J. Med. 1999, 341, 1725-1730. [CrossRef]

4. Lamb, K.E.; Lodhi, S.; Meier-Kriesche, H.-U. Long-term renal allograft survival in the United States: A critical reappraisal. Am. J. Transplant. 2011, 11, 450-462. [CrossRef] [PubMed]

5. Bunnapradist, S.; Neri, L.; Wong, W.; Lentine, K.L.; Burroughs, T.E.; Pinsky, B.W.; Takemoto, S.K.; Schnitzler, M.A. Incidence and Risk Factors for Diarrhea Following Kidney Transplantation and Association With Graft Loss and Mortality. Am. J. Kidney Dis. 2008, 51, 478-486. [CrossRef] 
6. Pant, C.; Deshpande, A.; Larson, A.; O'Connor, J.; Rolston, D.D.K.; Sferra, T.J. Diarrhea in solid-organ transplant recipients: A review of the evidence. Curr. Med. Res. Opin. 2013, 29, 1315-1328. [CrossRef]

7. Lee, J.R.; Magruder, M.; Zhang, L.; Westblade, L.F.; Satlin, M.J.; Robertson, A.; Edusei, E.; Crawford, C.; Ling, L.; Taur, Y.; et al. Gut microbiota dysbiosis and diarrhea in kidney transplant recipients. Am. J. Transplant. 2019, 19, 488-500. [CrossRef]

8. Ríos-Covián, D.; Ruas-Madiedo, P.; Margolles, A.; Gueimonde, M.; De los Reyes-Gavilán, C.G.; Salazar, N. Intestinal short chain fatty acids and their link with diet and human health. Front. Microbiol. 2016, 7, 185. [CrossRef]

9. Morrison, D.J.; Preston, T. Formation of short chain fatty acids by the gut microbiota and their impact on human metabolism. Gut Microbes 2016, 7, 189-200. [CrossRef]

10. Holscher, H.D. Dietary fiber and prebiotics and the gastrointestinal microbiota. Gut Microbes 2017, 8, $172-184$. [CrossRef]

11. Chaudhary, P.P.; Gaci, N.; Borrel, G.; O’Toole, P.W.; Brugère, J.F. Molecular methods for studying methanogens of the human gastrointestinal tract: Current status and future directions. Appl. Microbiol. Biotechnol. 2015, 99 , 5801-5815. [CrossRef] [PubMed]

12. Nakamura, N.; Lin, H.C.; McSweeney, C.S.; Mackie, R.I.; Gaskins, H.R. Mechanisms of Microbial Hydrogen Disposal in the Human Colon and Implications for Health and Disease. Annu. Rev. Food Sci. Technol. 2010, 1, 363-395. [CrossRef] [PubMed]

13. Sahakian, A.B.; Jee, S.R.; Pimentel, M. Methane and the gastrointestinal tract. Dig. Dis. Sci. 2010, 55, 2135-2143. [CrossRef] [PubMed]

14. Dridi, B.; Henry, M.; El Khéchine, A.; Raoult, D.; Drancourt, M. High prevalence of Methanobrevibacter smithii and Methanosphaera stadtmanae detected in the human gut using an improved DNA detection protocol. PLoS ONE 2009, 4, 1-6. [CrossRef]

15. Miller, T.L.; Wolin, M.J.; De Macario, E.C.; Macario, A.J.L. Isolation of Methanobrevibacter smithii from human feces. Appl. Environ. Microbiol. 1982, 43, 227-232. [CrossRef] [PubMed]

16. Ghavami, S.B.; Rostami, E.; Sephay, A.A.; Shahrokh, S.; Balaii, H.; Aghdaei, H.A.; Zali, M.R. Alterations of the human gut Methanobrevibacter smithii as a biomarker for inflammatory bowel diseases. Microb. Pathog. 2018, 117, 285-289. [CrossRef]

17. Eisenga, M.F.; Gomes-Neto, A.W.; van Londen, M.; Ziengs, A.L.; Douwes, R.M.; Stam, S.P.; Osté, M.C.J.; Knobbe, T.J.; Hessels, N.R.; Buunk, A.M.; et al. Rationale and design of TransplantLines: A prospective cohort study and biobank of solid organ transplant recipients. BMJ Open 2018, 8, e024502. [CrossRef]

18. Gavin, J.R.; Alberti, K.G.M.M.; Davidson, M.B.; DeFronzo, R.A.; Drash, A.; Gabbe, S.G.; Genuth, S.; Harris, M.I.; Kahn, R.; Keen, H.; et al. Report of the expert committee on the diagnosis and classification of diabetes mellitus. Diabetes Care 2003, 26, 5-20.

19. De Lacy Costello, B.P.J.; Ledochowski, M.; Ratcliffe, N.M. The importance of methane breath testing: A review. J. Breath Res. 2013, 7, 024001. [CrossRef]

20. Levitt, M.D.; Hirsh, P.; Fetzer, C.A.; Sheahan, M.; Levine, A.S. H2 excretion after ingestion of complex carbohydrates. Gastroenterology 1987, 92, 383-389. [CrossRef]

21. Yu, Z.; Morrison, M. Improved extraction of PCR-quality community DNA from digesta and fecal samples. Biotechniques 2004, 36, 808-812. [CrossRef] [PubMed]

22. De Goffau, M.C.; Luopajärvi, K.; Knip, M.; Ilonen, J.; Ruohtula, T.; Härkönen, T.; Orivuori, L.; Hakala, S.; Welling, G.W.; Harmsen, H.J. Fecal Microbiota Composition Differs Between Children With b-Cell Autoimmunity and Those Without. Diabetes 2013, 62, 1238-1244. [CrossRef] [PubMed]

23. Johnston, C.; Ufnar, J.A.; Griffith, J.F.; Gooch, J.A.; Stewart, J.R. A real-time qPCR assay for the detection of the nifH gene of Methanobrevibacter smithii, a potential indicator of sewage pollution. J. Appl. Microbiol. 2010, 109, 1946-1956. [CrossRef] [PubMed]

24. Samuel, B.S.; Hansen, E.E.; Manchester, J.K.; Coutinho, P.M.; Henrissat, B.; Fulton, R.; Latreille, P.; Kim, K.; Wilson, R.K.; Gordon, J.I. Genomic and metabolic adaptations of Methanobrevibacter smithii to the human gut. Proc. Natl. Acad. Sci. USA 2007, 104, 10643-10648. [CrossRef]

25. Levitt, M.D.; Furne, J.K.; Kuskowski, M.; Ruddy, J. Stability of human methanogenic flora over 35 years and a review of insights obtained from breath methane measurements. Clin. Gastroenterol. Hepatol. 2006, 4, 123-129. [CrossRef] 
26. Cloarec, D.; Bornet, F.; Gouilloud, S.; Barry, J.L.; Salim, B.; Galmiche, J.P. Breath hydrogen response to lactulose in healthy subjects: Relationship to methane producing status. Gut 1990, 31, 300-304. [CrossRef]

27. Christl, S.U.; Gibson, G.R.; Cummings, J.H. Role of dietary sulphate in the regulation of methanogenesis in the human large intestine. Gut 1992, 33, 1234-1238. [CrossRef]

28. Gibson, G.R.; Cummings, J.H.; Macfarlane, G.T.; Allison, C.; Segal, I.; Vorster, H.H.; Walker, A.R. Alternative pathways for hydrogen disposal during fermentation in the human colon. Gut 1990, 31, 679-683. [CrossRef]

29. Smith, N.W.; Shorten, P.R.; Altermann, E.H.; Roy, N.C.; McNabb, W.C. Hydrogen cross-feeders of the human gastrointestinal tract. Gut Microbes 2019, 10, 270-288. [CrossRef]

30. Roediger, W.E.W.; Duncan, A.; Kapaniris, O.; Millard, S. Reducing sulfur compounds of the colon impair colonocyte nutrition: Implications for ulcerative colitis. Gastroenterology 1993, 104, 802-809. [CrossRef]

31. Leonel, A.J.; Alvarez-Leite, J.I. Butyrate: Implications for intestinal function. Curr. Opin. Clin. Nutr. Metab. Care 2012, 15, 474-479. [CrossRef] [PubMed]

32. Perman, J.A.; Modler, S. Glycoproteins as Substrates for Colonic Bacterial Flora. Gastroenterology 1982, 83, 388-393. [CrossRef]

33. Gibson, G.R.; Cummings, J.H.; Macfarlane, G.T. Use of a three-stage continuous culture system to study the effect of mucin on dissimilatory sulfate reduction and methanogenesis by mixed populations of human gut bacteria. Appl. Environ. Microbiol. 1988, 54, 2750-2755. [CrossRef] [PubMed]

34. Eutamene, H.; Beaufrand, C.; Harkat, C.; Theodorou, V. The role of mucoprotectants in the management of gastrointestinal disorders. Expert Rev. Gastroenterol. Hepatol. 2018, 12, 83-90. [CrossRef]

35. Miller, T.L.; Wolin, M.J. Enumeration of Methanobrevibacter smithii in human feces. Arch. Microbiol. 1982, 131, 14-18. [CrossRef]

36. Miller, T.L.; Wolin, M.J. Methanosphaera stadtmaniae gen. nov., sp. nov.: A species that forms methane by reducing methanol with hydrogen. Arch. Microbiol. 1985, 141, 116-122. [CrossRef]

37. Miller, T.L.; Wolin, M.J. Oxidation of Hydrogen and Reduction of Methanol to methane.pdf. J. Bacteriol. 1983, 153, 1051-1055. [CrossRef]

38. Lecours, P.B.; Marsolais, D.; Cormier, Y.; Berberi, M.; Haché, C.; Bourdages, R.; Duchaine, C. Increased prevalence of methanosphaera stadtmanae in inflammatory bowel diseases. PLoS ONE 2014, 9, 1-7. [CrossRef]

39. Bang, C.; Weidenbach, K.; Gutsmann, T.; Heine, H.; Schmitz, R.A. The intestinal archaea Methanosphaera stadtmanae and Methanobrevibacter smithii activate human dendritic cells. PLoS ONE 2014, 9, 1-9. [CrossRef]

40. Chaudhary, P.P.; Conway, P.L.; Schlundt, J. Methanogens in humans: Potentially beneficial or harmful for health. Appl. Microbiol. Biotechnol. 2018, 102,3095-3104. [CrossRef]

41. Scanlan, P.D.; Shanahan, F.; Marchesi, J.R. Human methanogen diversity and incidence in healthy and diseased colonic groups using mcrA gene analysis. BMC Microbiol. 2008, 8, 1-8. [CrossRef] [PubMed]

42. Triantafyllou, K.; Chang, C.; Pimentel, M. Methanogens, methane and gastrointestinal motility. J. Neurogastroenterol. Motil. 2014, 20,31-40. [CrossRef] [PubMed]

43. Vakili, S.T.T.; Taher, M.; Ebrahimi Daryani, N. Update on the management of ulcerative colitis. Acta Med Iran. 2012, 50, 363-372.

44. Deepak, P.; Bruining, D.H. Update on the Medical Management of Crohn's Disease. Curr. Gastroenterol. Rep. 2015, 17, 1-10. [CrossRef] [PubMed]

45. Jia, Y.; Li, Z.; Liu, C.; Zhang, J. Methane Medicine: A Rising Star Gas with Powerful Anti-Inflammation, Antioxidant, and Antiapoptosis Properties. Oxid. Med. Cell. Longev. 2018, 2018, 1912746. [CrossRef] [PubMed]

46. Nafar, M.; Sahraei, Z.; Salamzadeh, J.; Samavat, S.; Vaziri, N.D. Oxidative stress in kidney transplantation causes, consequences, and potential treatment. Iran. J. Kidney Dis. 2011, 5, 357-372. [PubMed]

47. Boros, M.; Ghyczy, M.; Irces, D.; Varga, G.; Tokés, T.; Kupai, K.; Torday, C.; Kaszaki, J. The anti-inflammatory effects of methane. Crit. Care Med. 2012, 40, 1269-1278. [CrossRef]

48. Chen, O.; Ye, Z.; Cao, Z.; Manaenko, A.; Ning, K.; Zhai, X.; Zhang, R.; Zhang, T.; Chen, X.; Liu, W.; et al. Methane attenuates myocardial ischemia injury in rats through anti-oxidative, anti-apoptotic and anti-inflammatory actions. Free Radic. Biol. Med. 2016, 90, 1-11. [CrossRef]

49. Wolf, P.G.; Biswas, A.; Morales, S.E.; Greening, C.; Gaskins, H.R. H2 metabolism is widespread and diverse among human colonic microbes. Gut Microbes 2016, 7, 235-245. [CrossRef] 
50. Christl, S.U.; Murgatroyd, P.R.; Gibson, S.R.; Cummings, J.H. Production, metabolism, and excretion of hydrogen in the large intestine. Gastroenteroology 1992, 102, 1269-1277. [CrossRef]

51. Santos-Marcos, J.A.; Rangel-Zuñiga, O.A.; Jimenez-Lucena, R.; Quintana-Navarro, G.M.; Garcia-Carpintero, S.; Malagon, M.M.; Landa, B.B.; Tena-Sempere, M.; Perez-Martinez, P.; Lopez-Miranda, J.; et al. Influence of gender and menopausal status on gut microbiota. Maturitas 2018, 116, 43-53. [CrossRef] [PubMed] 